\title{
Normas aplicables en el procedimiento expropiatorio por las Entidades locales
}

por

\section{FRANCISCO RODRIGUEZ HARO}

Secretario Diplomado de Administración Local

La redacción del artículo 85 de la Ley de Expropiación forzosa de 16 de diciembre de 1954 y determinados preceptos de su Reglamento de 26 de abril de 1957, han sembrado cierta confusión respecto a las normas aplicables en las expropiaciones que se lleven a cabo por las Entidades locales.

Vamos a terciar, con nuestro modesto criterio, en esta enrevesada cuestión, en el deseo de que, si no se estimara acertado o correcto, contribuya, por lo menos, a un fructífero contraste de opiniones que permita hacer luz sobre el asunto.

\section{NORMAS VIGENTES}

I. Como principales :

El artículo $1 .^{\circ}-\mathrm{c}$ de1 Decreto de 23 de diciembre de 1955 (dictado en virtud de la disposición final tercera de la Ley de Expropiación de 16 de diciembre de 1954) dispone que continuarän en vigor: "Las disposiciones que regulan las expropiaciones que se lleven a cabo por razón de urbanismo y las que afectan a expropiaciones que, en cualquier caso, realicen las Entidades iocales, con las modificaciones contenidas en el articulo 85 de la Ley". 
Esas disposiciones son las siguientes:

a) Ley de Régimen local, articulada, de 24 de junio de 1955.

b) Ley de Régimen del Suelo, de 12 de mayo de 1956.

c) Reglamento de Bienes locales, de 27 de mayo de $\mathbf{1 9 5 5 .}$

d) Reglamento de Servicios loca'es, de $\mathbf{1 7}$ de junio de $\mathbf{1 9 5 5 .}$

Todas ellas posteriores a ia Ley de Expropiación de 16 de diciembre de 1954.

e) Reglamento de Obras locales de 14 de julio de 1924, anteriar a dicha Ley y vigente, parcialmente, por la disposicion transitoria undécima de la Ley de Régimen local de 24 de junio de 1955.

f) $Y$, por remisión de algunas de esas disposiciones, la propia Ley de Expropiación de 16 de diciembre de 1954, en los siguientes casos:

1. Artículos 29, 30, 31, 34 y 35 en materia de indemnización a inquilinos en el desahucio administrativo cuando no se llegare a una avenencia, según el artículo 116 del Reglamento de Bienes de 27 de mayo de 1955.

$2 .^{\circ}$ En valoraciones de terrenos, por aplicación de la Ley del Sue"o de 12 de mayo de 1956, según ésta dispone en sus ar-. tículos 85 y 89 .

\section{Como supletorias :}

1. Ley de Expropiación forzosa de 16 de diciembre de 1954, por disponerlo así :

a) Párrafo último del artículo $10^{\circ}$ del Decreto de 23 de diciembre de 1955, que to establece respecto a las disposiciones que comprende en su letra $c$ ), o sea, las que regulan las expropiaciones que por razón de urbanismo y en cudlquier caso realicen las Entidades locales.

b) Artículo 85. de la propia Ley, en esas expropiaciones urbanisticas locales, en lo no previsto en la Ley de Régimen local y demás aplicables (a lo local).

c) Artículo 55 del Reglamento de Servicios de 17 de junio de 1955 (posterior a la Ley de Expropiación). 
d) Artículo 105 del Reglamento de Obras de 14 de julio de 1924 (que lo dispone respecto a la Ley anterior de 10 de enero de 1879 ).

2. Reglamento de la Ley de Expropiación, de 26 de abril de 1957, como derivado y complemento de esta Ley.

Dos casos hemos de considerar especialmente con referencia a las vigencias antes sentadas:

A) Aplicación del Reg:amento de Obras municipales de 14 de julio de 1924.

La disposición transitoria undécima del texto refundido de la Ley de Régimen local de 24 de junio de 1955 (que coincide literalmente con la también undécima del anterior texto de $\mathbf{1 6}$ de diciembre de 1950), dice: Hasta que se publiquen los Reglamentos para la aplicación de la presente Ley, seguirán provisionalmenite, en cuanto no se opongan a ella, las disposiciones reglamentarias actualmente en vigor. $\mathrm{Y}$ a tal respecto, tenemos que:

El Reglamento de 2 de julio de 1924, sobre Población y términos municipales, ha sido sustituido por el de $\mathbf{1 7}$ de mayo de 1952.

El de igual fecha para los contratos municipales, lo ha sido por el de Contratación de $\mathbf{9}$ de enero de $\mathbf{1 9 5 3}$.

El de Organización y funcionamiento de los Ayuntamientos de 10 de julio de 1924, por el de 17 de mayo de 1952, llamado también de "Régimen jurídico", por lo que sustituye, igualmen te, al de Procedimiento de 23 de agosto de 1924 .

El de Funcionarios de 23 de agosto de 1924 y de Empleados administrativos de 14 de mayo de 1928, por el general de Funcionarios de $\mathbf{3 0}$ de mayo de $\mathbf{1 9 5 2}$.

El de Sanidad de 9 de febrero de 1925, por el de Funcionarios Sanitarios locales de 27 de noviembre de 1953 .

El de Hacienda de 23 de agosto de 1.924, por el de 4 de igual mes de 1952.

Pero el de Obras, Servicios y Bienes municipa'es de 14 de julio de 1924, sólo ha sido reemplazado parcialmente por el de 
Bienes de 27 de mayo de 1950 ; y, en su título II, por el de Servicios de 17 de junio de igual año.

Sin embargo, en cuanto a obras no se ha dictado aún el Reglamento que recoja la normativa específica que se desarrolla en su extenso título I, sin que estimemos -como algunos compapañeros lo hacen- que haya quedado suplido por preceptos tan completos como los de la Ley del Suelo, porque la casuística no es propia de una Ley, norma principal, sino que es ésta la que precisa de una discriminación o regulación al detalle de sus disposiciones, máxime si se trata de una Ley tan compieja y trascendental como la de 12 de mayo de 1956, muy precisada de aclaración mediante otras normas secundarias. $Y$ en cuanto a materia tan importante como la que dicho viejo Reglamento desenvuelve en su título III - rDe la expropiación forzosa por utilidad pública municipaln- no se puede considerar desarrollada casuísticamente con los preceptos del título II del nuevo Reglamento de Bienes, pues sólo regulan una secueı de la expropiación, el "desahucio por vía administrativa"; ni con los comprendidos en. la sección segunàa - subsección primera- del capítulo III, título III - (municipalizaciones y provincializaciones"- de! de Servicios; sino que las normas contenidas en los artículo 105 al 125 del repetido Reglamento de 14 de julio de 1924 las estimamos muy útiles y necesarias como complementarias de la Ley de Régimen local. ^.

Hemos, pues, de considerarlo en vigor, no sólo porque no si ha daào una disposición expresamente derogatoria (como sería lógico si el propósito del legislador hubiera sido el dejar sin aplicación tal cuerpo reglamentario); sino porque después de publicados todos los Reglamentos de las actividades administrativas locales, el nuevo texto refundiido de la Ley de 24 de junio de 1955, sigue insertando la disposición transitoria undécima que sólo pucde referirse ya al de Obras de 14 de julio de 1924, en sus titulos I y III en cuanto no se opongan a las normas generales.

B) Aplicación del artículo 85 de la Ley de Expropiación de 16 de diciembre de 1954. 
Es terminante el artículo $1 .^{\circ}$ del Decreto de 23 de diciembre de 1955, al declarar en vigor: ' $(c)$ Las disposiciones que regulan las expropiaciones que se lleven a cabo por razón de urbanismo. y las que afectan a las expropiaciones que, en cualquier caso, realicen las entidades locales, con las modificaciones contenidas en el artículo 85 de la Ley".

A su vez este artículo 85, dice: “Las expropiaciones que se lleven a cabo por razón de urbanismo y las que en cualquier caso realicen las entidades locales, se ajustarán a lo expresamente dispuesto en la Ley de Régimen local y demás aplicables, y en lo no previsto en ellas, a.l contenido de la presente, con las modificaciones siguientes:

Primera. Para la determinación del justo precio se seguirán las reglas y el procedimiento establecido en el capitulo tercero del título segundo de esta Ley. (Arts. 24 al 47).

Segunda. En el Jurado provincial de Expropiación, el funcionario técnico a que se refiere el apartado b) del artícu'o treinta y dos "será designado por la Corporación local interesada" (que por Orden del Ministerio de Justicia de 10 de julio de 1958, a virtud de escrito razonado del Excmo. Ayuntamiento de Valencia, ante el Servicio Nacional de Inspección y Asesoramiento, se dispone que "podrá recaer en un Arquitecto municipal", y no de entre los que estén "al servicio de la Hacienda", como dice el referido artículo 32 , apartado $b$ ).

Del estudio comparado de ambos textos, letra $c$ ) de! artículo $1 .^{\circ}$ del Decreto de 23 de diciembre de 1955 y párrafo primero del artículo 85 de la Ley de Expropiación, caben dos interpretaciones :

Primera.-Que si bien se declaran aplicables en las expropiaciones locales sus disposiciones específicas, las modificaciones contenidas en el artículo 85 de la Ley general sobre la materia, deben tenerse en cuenta; y tales modificaciones son las de determinar el justo precio por las normas del capítulo tercero del título segundo de dicha Ley.

$Y$ ello porque cuando ésta se promulgaba en 16 de diciembre de 1954, el artículo 149 de la de Régimen local -tal como apa- 
rece !iteralmente en su actual texto refundido de 24 de junio de 1955 - está ya recogido en e! de 16 de diciembre de 1950, o sea, desde cuatro años antes, por lo que el legislador no pudo ignorarlo al redactar ei artículo 85 de la Ley de Expropiación; y tan no lo ignora que, cuando dicta el artículo $1^{\circ}$ del Decreto de 23 de diciembre de $1955-$ posterior al texto refundido de la de Régimen local, que sigue insertando el artículo 149-, "remacha el clavo" al decir que "continuarán en vigor": c) las disposiciones que regulan las expropiaciones que se lleven a cabo por razón de urbanismo y las que afectan a expropiaciones que, en cualquier caso, realicen las Entidades locales, con las modificaciones contenidas en el artículo 85 de la Ley, sin que e! párrafo final de este artículo $10^{\circ}$ que consideramos, al decir: "En lo no previsto en los preceptos a que hacen referencia los apartados $c$ ) y $d$ ), regirá como supletoria la Ley de 16 de diciembre de 1954 ", contradiga, a nuestro juicio, el precepto expreso antes transcrito, porque esta Ley a que remite como supletoria, en su tan debatido artículo 85, también dice que en lo no previsto en ellas (en esas mismas disposiciones que éste enumera al principio del párrafo y que coinciden con las del apartado $c$ ) del artículo $10^{\circ}$ del Decreto), se estará al contenido de la presente, con las modificaciones siguienties.

Si esto no fuera así, si el propósito del legislador no hubiera sido, conociendo el texto del artículo 149 de la Ley de Régimen local de 1950, eliminar el sistema de justiprecio de éste por el del capítulo tercero del título segundo de la Ley de 1954, ¿qué justificación tiene la inserción en ésta de su artículo 85?; y, conocida la subsistencia en el texto refundido de la Ley de Régimen local de 24 de junio de 1955 , del mismo artículo 149 , ¿qué finalidad tendría el artículo $1 .^{\circ}$ del Decreto de 23 de diciembre de igual año, al respetar las normas expropiatorias por razón de urbanismo y por otros fines locales, aclarando expresamente que "con las modificaciones contenidas en el artículo 85 de la Ley" de 1954 ?

$\mathrm{Y}$ aún hay más, puesto que numerosos preceptos del Reglamento de la Ley, de 26 de abril de 195\%, muy posterior a to- 
das esas normas que analizamos, parecen concordar o afianzar ese propósito; y así podemos observar cómo al ocuparse de la determinación del justo precio, en su artículo 25, letra $d^{d}$ ), habla del "wacuerdo del Ministerio o, en su caso, del órgaro competente de la Corporación local o Entidad respectivan.

Al hablar del pago, su artículo 48, dice: “1. ${ }^{\circ}$ Determinado el justo precio por cualquiera de los procedimientos previstos en el capítulo III del título II de la Ley, se remitirá el expediente al Ministerio que corresponda o a la Diputación provincıal o Ayuntamiento que hayan acordado la expropiación".

Los artículo $3 .^{\circ}-2$ y 4 ; citado 48 ; 133-2; 134-1 y 4 ; y 135 en orden a titularidad para expropiar, a adopción de acuerdos, pago del precio, reclamaciones y responsabilidades e indemnización por daños, aluden también a las Corporaciones locales.

$\mathrm{Su}$ artículo 102, dice: "Las expropiaciones que se realicen por razón de urbanismo se ajustarán a lo dispuesto en la Ley de Régimen del Suelo y disposiciones vigentes o que puedan dictarse en lo sucesivo sobre dicha materian; y ya hemos visto que la Ley del Suelo en sus artículos 85 y 89 , en materia de valoración de terrenos, se remite, a su vez, a los criterios establecidos por la Ley de Expropiación.

Finalmente, el artículo 101 del Reglamento de dicha Ley, prescribe: "1." Lo dispuesto en "l artículo 85 de la Ley será de aplicación a las expropiaciones llevadas a cabo por ias Entidades locales referentes a obras o serricios incluidos en los planies o proyectos municipales o provinciales. ; y, aún de modo más contundente:

"2. Cuando scan beneficiarias (las Entidades locales) se apiicarán llas disposiciones generales de la Ley de Expropiación forzosan.

Se deduce de todo ello que el criterio del legiislador, según los preceptos que dejamos transcritos del Reglamento de 26 de abril de 1957 -posterior al nuevo texto articulado de la Ley de Régimen locai y a la Ley de Régimen del Suelo, e incluso al Decreto de 23 de diciembre de 1955 -es el de la aplicación de la Ley de Expropiación, en orden a la determinación del justo 
precio, siempre, y solo cumo supletoria en otros trámites o incidencias no previstas, a los planes y proyectos de ias Entidades locales; si bien es de extrañar la condición de "cuando sean beneficiarias", pues la regla general es que siempre lo sean, y cuando, por excepción, las expropiaciones vayan en beneficio de las "entidades y concesionarios" o de cualquicr "persona natural o jurídican, conforme al artículo $2:$, apartados 2 y 3 y artículo 14 de la propia Ley de Expropiación; y apartado 2 del artículo 52, o número 1 del 146 de la Ley del Suelo, ¿qué otras disposiciones habrán de aplicarse que no sean las de esta Ley de Expropiación?

Puede darse el caso de que el expropiante sea el Municipio y el beneficiario el Estado, en el supuesto del artículo 145 de la Ley de Régimen local cuando autoriza la expropiación de edificios crespecto a los cuales el Municipio tenga adquirido compromiso firme de ceder en el momento oportuno al Estado, Provincia o una Entidad pública, para destinarlos a fines que redunden en pro de los intereses de la comunidad municipal» (Adquisición de un edificio para cederlo a la Dirección General de Correos, por ejemplo; o al Ministerio de Educación para alojar un Instituto o Escuela; o al del Ejército, para cuartel, etcétera, 'etc.).

En este caso en que la Entidad local expropiante no es beneficiaria, sino el Estado, ¿se hace caso omiso de la Ley de Expropiación -a tenor del número 2 del artículo 101 de su Reglamento-y se aplica la Ley de Régimen local exclusivamente?... Ello no es lógico. Creemos que, en este caso, como en todos en los que un ente local sea el expropiante, se aplicará la Ley de Régimen local; pero con las modificaciones del artículo 85 de la de Expropiación.

Finalmente, puede ocurrir que el expropiante sea el Estado o una Entidad paraestatal, y el beneficiario un ente 'ocal, pero tampoco se explica la condición, porque en estos casos es indudable que el expropiante no es Entidad local y no puede, por tanto, aplicar la Ley de Régimen local, sino la generdil de Expropiación. 
Segunda.-La otra interpretación que se da al artículo $\mathbf{8 5}$ de la Ley, pues de otro modo no se explica su inserción en la misma, es, no leyendo en su acepción literal, sino en su espíritu o intención, la siguiente:

"Las expropiaciones que se lleven a cabo por razón de urbanismo y las que en cualquier caso realicen las Entidade's locales; se ajustarán a lo expresamente dispuesto en la Ley de Régimen local y demás aplicables" y sólo en lo no previsto em ellas (en esa Ley y demás aplicables) al contenido de la Ley de Expropiación; y, en caso de aplicar ésta -siempre como supletoria, entienden-, se hará con ias modificaciones que respecto a la determinación del justo precio, funcionario técnico representante de la Administración en el Jurado de Expropiación y transferencia de las facultades de dicha Administración o autoridades gubernativas a las Corporaciones locales o a los organismos que en los asuntos de éstas intervienen, disponen las modificaciones primera, segunda y tercera de dicho artículo, "sin limiłación de la autonomía que se les concede en las disposiciones vigentes".

Luego a juicio de los que mantienen esta segunda interpretación del artículo 85, en las expropiaciones locales deben aplicarse los artículos 149, 171 y demás de la Ley de Régimen local, así como los preceptos de sus Reglamentos, incluído el. de Obras de 14 de julio de 1924; y la Ley del Suelo de 12 de mayo de 1956 ; quedando siempre como supletoria la Ley de Expropiación.

Nosotros estamos más con la primera interpretación que con la segunda ; pero no con que, como dice el artículo 101-2 del Reglamento de 26 de abril de 1957, cuando las Entidades locales "sean beneficiarias, se aplicarán las disposiciones generales de la Ley de Expropiación forzosa", ya que, como hemos objetado, todos los casos de expropiación por las Entidades locales quedarían sujetos a ésta ; sino, como establecen el artículo $\left.1 .^{\circ}-c\right)$ deJ Decreto de 23 de diciembre de 1955: "con las modificaciones contenidas en el artículo 85 de la Ley", que, según dispone el 
NORMAS APLICABLES EN EL PROCEDIMIENTO EXPROPIATORIO

artículo 101 del referido Reglamento: “será de aplicación a las expropiaciones llevadas a cabo por las Entidades loca'es referentes a obras o servicios incluídos en planes o proyectos municipales o provinciales".

O sea, que así como la Ley de Régimen del Suelo en cuanto a valoraciones de terrenos (arts. 85 y 89), se remite a las normas y criterios, al respeto, de la Ley de Expropiacion, la Ley de Régimen local y sus Reglamentos -incluído el de Obrasserán de aplicación a las expropiaciones que en general realicen las Entidades locales, excepto para la determinación del justo precio que "se seguirán las reglas y procedimiento establecidos en el capítulo tercero del título segundo de esta Ley!", la de Expropiación (según su tan manoseado artículo 85, modificación primera).

Ello, naturalmente, con las excepciones establecidas por preceptos ya citados, como el artículo 55 del Reglamento de Servicios de 17 de junio de 1955 , que reduce la aplicación de la Ley de Expropiación a un valor supletorio - rigiéndosc los justiprecios por los preceptos de este Reglamento y artículo 171 de la Ley de Régimen local-; y el de la indemnización a ocupantes -en el desahucio administrativo- que se regulará por el Reglamento de Bienes de 27 de mayo de 1955, salvo cuando no haya avenencia, en cuyo caso se aplicará el procedimiento de los artículos de la Ley de Expropiación a que remite el 116 de dicho Reglamento. 